\title{
Entrevista/Interview/Entrevista
}

Revista Brasileira de Extensão Universitária

v. 6, n. 1, p. 59-62 (2015)

e-ISSN 2358-0399

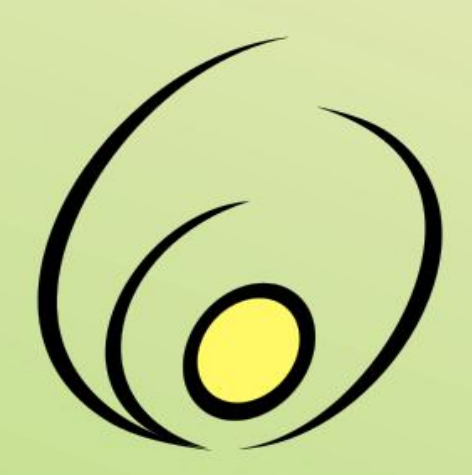

Fórum de

Pró-Reitores

de Extensão

das Instituições

Públicas de

Educação Superior

Brasileiras

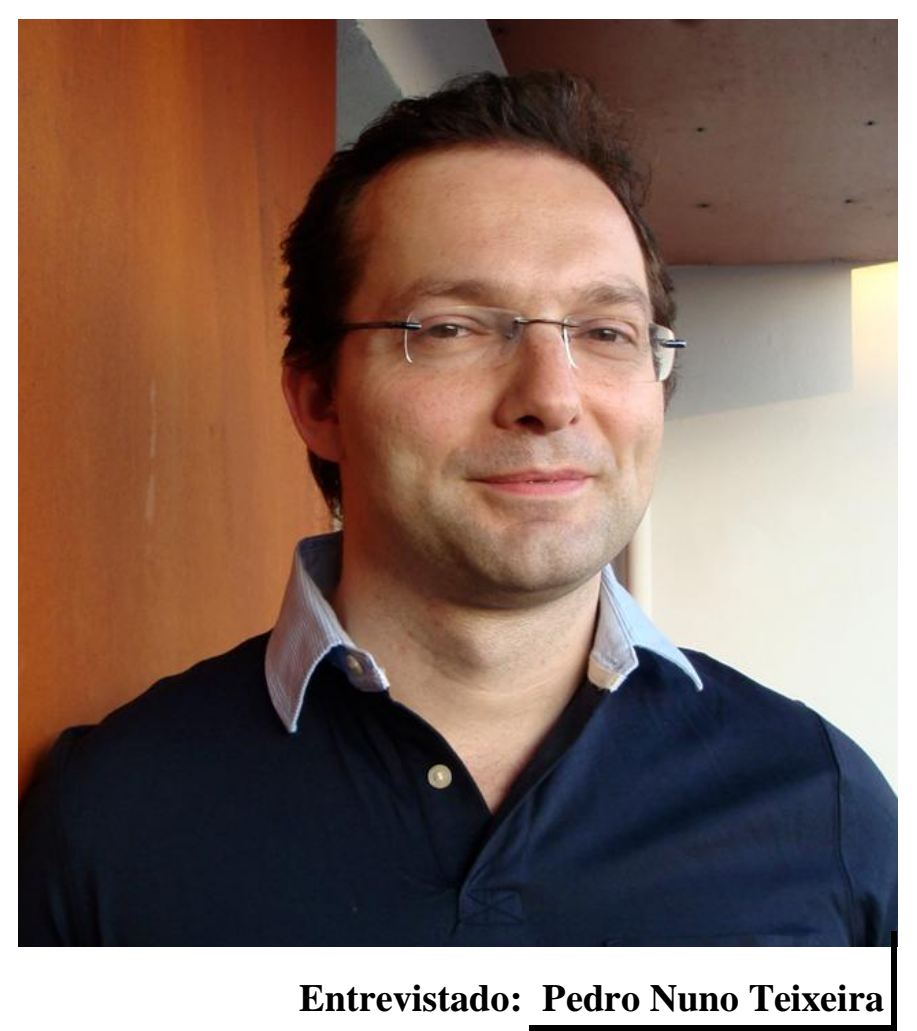

\section{Extensão Universitária na Europa: A Terceira}

\section{Missão}

Em vários países, o interesse por maior abertura e integração das universidades ao meio social e econômico é crescente. Impulsionada pela sociedade e economia do conhecimento e pelas demandas sociais, a Extensão Universitária ganha cada vez mais importância, seja na América Latina onde o foco principal são ações sociais diretas, intervenções promotoras da cidadania e fomentadoras do protagonismo local, seja em economias mais desenvolvidas onde os serviços e a transferência de tecnologia recebem maior atenção. Na Europa continental o termo correlato à extensão mais adotado é "Terceira Missão" (Third Mission) ${ }^{1}$, e subdividese em três sub-áreas: Educação Continuada, Transferência de Tecnologia e Inovação, e Engajamento Social. Este campo de atuação da academia também ganha força no "velho continente". 
Para entender mais sobre esta realidade em Portugal e na Europa, nesta edição da Revista Brasileira de Extensão Unviersitária (v. 6 n. 1) entrevistamos o professor PhD Pedro Nuno Teixeira, da Faculdade de Economia e atualmente Vice-Reitor de Formação e Organização Acadêmica da Universidade do Porto, Portugal. Nosso entrevistado também exerce a função de diretor do Centro de Investigação de Políticas do Ensino Superior (CIPES), uma associação privada fundada pelas Universidades do Porto e de Aveiro, e aberto a outras instituições de ensino superior; atualmente é um dos maiores centros do mundo dedicados à investigação do ensino superior. Segundo o entrevistado, em Portugal o CIPES tem como objetivo "fazer avançar o pensamento crítico e promover um entendimento informado sobre as questões vitais das políticas de ensino superior" ${ }^{2}$.

Respondendo um conjunto de questionamentos enviados por e-mail, o professor Pedro Nunes Teixeira compartilhou com a RBEU sua visão sobre a Extensão Universitária (Terceira Missão) no contexto europeu.

Revista Brasileira de Extensão Universitária: Como a Extensão Universitária é abordada no contexto das universidades portuguesas e europeias?

Pedro Nuno Teixeira: A questão da extensão universitária tem recebido uma atenção crescente das universidades portuguesas e europeias, embora existindo graus de desenvolvimento bastante diferenciados. Uma das principais razões para esta atenção crescente prende-se com a preocupação dos governos e das instituições de ensino superior para uma maior atenção às necessidades económicas e sociais e que as Universidades sejam capazes de contribuir decisivamente para esses domínios. Aliás, esta preocupação tem-se traduzido no facto de, em muitos países europeus, terem sido concretizadas reformas nos modelos de governo das universidades, as quais introduziram uma presença significativa de atores externos à universidade nesses órgãos de decisão. Por outro lado, a extensão universitária tem sido uma forma de obtenção de recursos, particularmente relevantes numa altura de contenção das fontes de financiamento tradicionais. Deste modo, o desenvolvimento tem uma dimensão duplamente virtuosa, contribuindo para uma maior ligação das Universidades ao seu entorno e, por outro lado, permitindo uma diversificação das fontes de financiamento. Finalmente, a terceira missão tem sido estimulada por uma consciência crescente do papel que as Universidades podem ter, além das missões tradicionais de ensino e de pesquisa científica. Assim, as Universidades podem desempenhar um papel importante na formação ao longo da vida e na transferência de conhecimento, contribuindo para a criação dum entorno favorável à disseminação e utilização de conhecimento.

\section{“... a terceira missão tem sido estimulada por uma consciência crescente do papel que as \\ Universidades podem ter, além das missões tradicionais de ensino e de pesquisa científica"}

RBEU: Quais as similaridades e diferenças dos conceitos de Extensão Universitária adotada na América Latina, em especial no Brasil, e o de Terceira Missão utilizado no meio acadêmico europeu?

PNT: Penso que algumas das tendências identificadas na questão anterior são também observáveis nos países da América Latina e no Brasil. Em ambos os continentes existe uma procura crescente dum papel mais activo das Universidades na relação com o seu contexto económico e social. 
No entanto, existem algumas diferenças. Por um lado, o papel do Estado no ensino superior tende a ser mais vincado na Europa. Por outro lado, os desafios económicos e sociais são mais complexos do lado da América Latina, pois coincidem processos de massificação do ensino superior com a vontade de se aproximar cada vez mais dos níveis de desenvolvimento educacional, científico e tecnológico das sociedades avançadas. Deste modo, as Universidades europeias beneficiam de poder lidar com os desafios da extensão num contexto de estabilização da procura e de fontes de financiamento estatal mais generosas do que as existentes em muitos países da América Latina.

RBEU: Quais os motivos por trás do crescente interesse em torno das atividades de Terceira Missão nas universidades européias? Existem diferenças nas abordagens dos diferentes países?

PNT: Algumas das principais razões para a primeira parte da questão já foram abordadas. Prendem-se com uma crescente aspiração nas sociedades e governos europeus para que a Europa seja uma sociedade cada vez mais baseada no conhecimento e de que as Universidades tenham um papel ativo nesse objetivo, o qual está para além das missões tradicionais de ensino e de pesquisa. No entanto, e apesar do forte processo de integração (também visível no ensino superior), a paisagem do ensino superior europeu é ainda muito diversa e isso também se reflete nestes aspetos. Há países com uma tradição muito mais forte de formação ao longo da vida e de grande envolvimento das Universidades nessas atividades. Noutros casos, esse papel é ainda um pouco reduzido. Por outro lado, o grau de desenvolvimento da estrutura económica e tecnológica dos países europeus (e das suas regiões) é ainda bastante diverso (sobretudo depois do alargamento a leste), o que cria oportunidades de transferência de conhecimento e de interação entre universidades e empresas muito diversas. Finalmente, o grau de diferenciação do tipo de instituições de ensino superior é muito diferente na Europa. Temos países com sistemas muito homogéneos, em que todas as instituições são relativamente parecidas nos seus perfis; e outros com graus significativos de diferenciação das missões institucionais, o que reflete no grau e no tipo de interações com os atores sociais envolventes. Há países europeus onde o contributo local ou regional é muito forte, especialmente para certo tipo de instituições de ensino superior, enquanto que noutros casos esse papel é ainda mais recente e menos desenvolvido.

... o grau de

desenvolvimento da

estrutura económica e

tecnológica dos países

europeus (e das suas

regiões) é ainda bastante

diverso (sobretudo depois

do alargamento a leste), o

que cria oportunidades de

transferência de

conhecimento e de

interação entre

universidades e empresas

muito diversas"

RBEU: Quais as áreas de conhecimento e atividades universitárias em que observa-se uma maior integração das universidades com a sociedade?

PNT: É difícil fazer uma apreciação global, sobretudo tendo em atenção a diversidade referida na resposta à questão anterior. Penso que se, tradicionalmente, a questão da formação ao longo da vida era uma atividade mais desenvolvida em muitas instituições, até por estar mais próxima das atividades e das competências de muitos docentes e investigadores, a questão da transferência de conhecimento e de inovação têm ganho uma importância fundamental em muitos países e na vida de muitas Universidades europeias. A valorização da inovação enquanto factor fundamental em termos económicos, sociais e culturais, tem dado um impulso decisivo nessas atividades, com o desenvolvimento, em muitas universidades europeias, de estruturas administrativas e técnicas de apoio ao desenvolvimento dessas atividades. Isso também começa a refletir-se nas atitudes e comportamentos de muitos docentes e investigadores, embora os mecanismos de compensação financeira e simbólica tardem a integrar esses contributos. 
RBEU: Como ocorre o processo de gestão/ avaliação das atividades da Terceira Missão nas universidades? Existem metodologias e indicadores definidos e de uso consolidado?

PNT: Este é um aspeto que tem recebido crescente atenção, havendo algumas iniciativas de consórcios europeus que têm procurado promover uma tipologia de indicadores que permitam medir e monitorizar essas atividades. No entanto, este aspeto é complexo devido a vários fatores. Um dos principais é a dificuldade em medir os impactos de muitas destas atividades, pois muitas delas apenas serão detectáveis após alguns anos. Por outro lado, há aspetos que são difíceis de medir no contributo económico, social e cultural do ensino superior quando estabelece relações de valorização e apropriação do conhecimento pelo seu entorno local, regional ou nacional. Finalmente, existe alguma fluidez na definição de quais atividades são claramente terceira missão (ou extensão) e quais são claramente pesquisa ou educação. De facto, algumas das mudanças já mencionadas, como sejam a evolução para uma sociedade e economia do conhecimento tende a esbater algumas dessas categorias, seja ao nível da formação, seja ao nível da pesquisa e aplicação de conhecimento.

RBEU: Quais as tendências para o futuro?

PNT: Penso que a tendência será de reforço das atividades de extensão na Europa, motivada pela dupla força de necessidade financeira e busca de legitimidade política e social. No entanto, ao mesmo tempo encontramos preocupações acerca duma excessiva orientação das universidades para as necessidades externas e para um enviesamento para as preocupações de curto prazo. Estas preocupações assentam no risco de uma menor sustentabilidade intelectual e criativa das instituições de ensino superior. Estas deverão procurar um equilíbrio entre a vontade de fortalecer relações cada vez mais intensas com os atores externos e a necessidade de alimentar o seu núcleo académico e científico. Por outro lado, também têm de equilibrar necessidades e prioridades de curto e de longo prazo, pois se uma instituição que apenas se preocupa com o longo prazo pode ter um problema de relevância e de legitimidade social, uma instituição que apenas se preocupa com os interesses imediatos pode esgotar a sua capacidade de criar novo conhecimento que permita alimentar essas relações com o exterior. Finalmente, creio que, no caso europeu, o grau e o tipo de atividades de extensão deverão ser uma força importante de diferenciação da paisagem universitária, na medida em que estejam adaptadas ao perfil e à missão específica de cada instituição de ensino superior.

"se uma instituição que
apenas se preocupa com o
longo prazo pode ter um
problema de relevância e
de legitimidade social,
uma instituição que
apenas se preocupa com
os interesses imediatos
pode esgotar a sua
capacidade de criar novo
conhecimento que
permita alimentar essas
relações com o exterior"

Esta entrevista foi mediada pelo professor Manoel Maximiano Junior (manoel.maximiano@fe.up.pt), docente da Universidade do Estado do Pará, atualmente cursando doutorado na Universidade do Porto onde, com apoio do CIPES, pesquisa sobre "Indicadores de melhoria de desempenho da Terceira Missão nas Universidades", com objetivo de estabelecer comparações e padrões de avaliação considerando as realidades acadêmicas brasileira e europeia.

\section{Notas}

1. Na Grã-Bretanha adota-se o termo Third Stream.

2. Para garantir a integridade das respostas, o texto foi mantido na ortografia original de Portugal.

$* * *$

Como citar esta entrevista:

TEIXEIRA, P. N. Extensão Universitária na Europa: A Terceira Missão. Entrevista concedida a Manoel Maximiano Junior. Revista Brasileira de Extensão Universitária, v. 6, n. 1, p. 59-62, 2015. Disponível em: <https://periodicos.uffs.edu. br/index.php/RBEU/article/view/3069/pdf > 